\title{
A TRANSMIDIALIDADE COMO ESTRATÉGIA DISCURSIVA
}

\section{TRANSMEDIALITY AS A DISCURSIVE STRATEGY}

SILVIA MARIA DE SOUSA*

RESUMO: 0 trabalho discute, à luz da semiótica do discurso, os conceitos de transmidiação e intermidialidade, buscando descrever estratégias enunciativas e modos de interação derivados da "convergência" (JENKINS, 2008) entre TV e internet. Elege-se como objeto de investigação telenovelas da Rede Globo e conteúdos a elas relacionados, disponibilizados no portal GShow (http://gshow.globo.com). A partir da formulação de uma "semiótica das práticas" (FONTANILLE, 2005; 2008), as denominadas narrativas transmidiáticas são tomadas como textos construídos em face da congregação de diferentes mídias: TV, computador, celular, livro, e-book, câmera fotográfica etc. Postula-se que esses textos condensam diferentes práticas semióticas e se expandem por meio de estratégias que envolvem múltiplas plataformas.

PALAVRAS-CHAVE: Narrativas transmidiáticas. Intermidialidade. Práticas Semióticas.

* Docente da UFF - Universidade Federal Fluminense. E-mail: silviams@id.uff.br . 
ABSTRACT: This paper discusses, under the perspective of French Semiotics, both transmediality and intermediality concepts, looking forward to describe the enunciative strategies and the modes of interaction that come from the "convergence" (JENKINS, 2008) between TV and internet. As object of analysis, we chose Rede Globo's soap operas and some data related to them available on GShow (http:// gshow.globo.com). Based on the formulation of a "semiotics of practices" (FONTANILLE, 2005; 2008), the so called "transmedia storytelling" are taken as texts arisen from the congregation of many media, such as TV, computer, mobiles, books, e-books, cameras etc. It is postulated that these texts condense different semiotics practices and are expanded through strategies that involve several media platforms.

KEYWORDS: Transmedia storytelling. Intermediality. Semiotic Practices.

Robôs, contas fantasmas no Twitter e um exército de militantes cibernéticos são os ingredientes usados, não para compor um filme de ficção, mas para auxiliar o presidente venezuelano a se tornar o líder político mais "retwittado" do mundo. A popularidade cibernética de Nicolás Maduro desbancou, inclusive, a do Papa Francisco. Em matéria sobre o tema, publicada no Globo de 04 de julho, é citada a afirmação do jornalista William Peña para quem " - 0 chavismo tem dois grandes aliados: os meios de comunicação tradicionais, controlados pelo Estado, e os robôs..." (BERGEN, 2015). O fato noticiado é usado como mote para iniciar este trabalho por evidenciar uma das questões centrais a serem tratadas: a 
concepção e o uso de estratégias (midiáticas, transmidiáticas, intermidiáticas) na produção e circulação de discursos, que, em última instância, acabam por constituir modos de viver e estar no mundo. Buscaremos, por meio de uma reflexão semiótica sobre as noções de transmidiação e intermidialidade, observar como as potencialidades das chamadas novas tecnologias reconfiguram a noção de texto e, consequentemente, os papéis e as posições dos enunciadores e enunciatários.

\section{Transmidiação e Intermidialidade}

O estudioso americano Henry Jenkins, ao desenvolver suas postulações sobre a cultura da convergência, define a narrativa transmídia como "a arte da criação de um universo" (JENKINS, 2008, p. 49). De acordo com esse raciocínio, a criação de narrativas cede lugar à criação de "ambientes atraentes que não podem ser completamente explorados ou esgotados em uma única obra, ou mesmo em uma única mídia" (JENKINS, 2008, p. 161). Jenkins abala a solidez da noção de narrativa ao evidenciar que, diante das ferramentas tecnológicas e dos apelos mercadológicos contemporâneos, as narrativas tornam-se complexos ambientes multimidiáticos, também chamados "universos". Com isso, o pesquisador põe em destaque importantes questões para a compreensão do que se denomina cultura da convergência e cultura participativa, especialmente ao serem observadas obras projetadas e financiadas por grandes conglomerados. Vale mencionar que a noção de transmídia cunhada por Jenkins obteve grande receptividade no Brasil, ainda que os também chamados "projetos transmídias" brasileiros sejam muito tímidos se comparados aos desenvolvidos pela indústria americana, tais 
como, Lost, Matrix, Harry Porter. Acreditamos que a discussão sobre a noção de transmidialidade carece de melhor delimitação teórica, ao mesmo tempo em que requer um conjunto mais amplo de análises que contemplem projetos variados em extensão e em propósitos. A nosso ver, é tarefa das teorias do discurso compreender o papel do emprego de múltiplas plataformas na produção, transmissão e circulação de textos. Diante disso, interrogamo-nos: a) como pensar no estatuto da criação artística, diante de projetos que envolvem uma gama de profissionais das mais diversas especialidades? b) de que modo delimitar e depreender a imagem de enunciador pressuposta em obras colaborativas e concretizadas em múltiplas mídias? Para elucidar a complexidade circundante aos projetos transmidiáticos, retomamos de Jenkins (2008, p. 36) o seguinte relato sobre alguns dos desafios da produção colaborativa entre o cinema e a indústria dos games:

Seriam relações difíceis de sustentar, já que todas as partes temiam perder o controle criativo, e já que o tempo necessário para o desenvolvimento e distribuição era radicalmente diferente. A empresa de games deveria tentar sincronizar seu relógio ao imprevisível ciclo de produção de um filme, na esperança de chegar ao Wal-Mart no mesmo fim de semana da estreia do filme? [...] 0 game seria lançado semanas ou meses após todo o barulho em torno do filme já ter acabado ou, pior, depois de o filme fracassar nas bilheterias? 0 game deveria se tornar parte do planejamento publicitário para um grande lançamento, mesmo que isso significasse iniciar o desenvolvimento antes mesmo de o estúdio dar "sinal verde" para a produção do filme? [...]

Arquitetar um universo requer estratégias bem alinhavadas. É preciso ajustar com precisão o tempo, os interesses e as competências dos criadores de um produto artístico-mi- 
diático. Além disso, cada vez mais, esse tipo de narrativa vai se construindo na dependência da participação ativa do enunciatário. Como prever e incorporar a participação fundamental e ardorosa dos fãs ajustando-a aos interesses da produção? Para a estudiosa das novas mídias Janet Murray, o futuro nos reserva o que chama de "ciberdrama". Essa "história digital" (MURRAY, 2003, p. 251) do futuro incluirá toda sorte de estratégias transmidiáticas e refinadíssimas peripécias participativas. As previsões de Murray (2003) pretendem explicar qual será o "futuro da narrativa no ciberespaço" e incluem a criação de espaços de discussão dentro do universo ficcional, a ativa interpretação de papéis por parte dos interatores (parceiros da interação), entre várias outras possibilidades. Em uma de suas previsões, a autora refere-se à criação de histórias de ação simultâneas:

Um filme sobre um jogo de pôquer ou um golpe de vigaristas poderia manter em segredo as motivações de cada protagonista em relação aos demais; uma vez que os espectadores seriam capazes de escolher qual personagem iriam acompanhar, diferentes membros do público assistiriam à mesma cena com informações bastante diferentes. As plateias de cinema seriam seduzidas a assistir novamente àquele filme a partir de um outro ponto de vista ou a acessar os pensamentos de um personagem cujas razões permaneceram ocultas da primeira vez. (MURRAY, 2003, p. 242)

A visão futurística de Murray está ancorada no inevitável avanço da técnica. Disso não é preciso duvidar, tampouco temer. $\mathrm{O}$ incômodo que origina tantas reflexões e debates, desconcerta pesquisadores de várias áreas e interfere no rumo de teorias do texto encontra-se nos novos e mutáveis modos de interação entre sujeitos e entre sujeitos e objetos. Quais seriam, se é que existem, os limites da participação? Murray preconiza 
a fusão de espaços interativos, "ambientes participativos", aos espaços da autoria. Segundo ela, "se ambientes participativos fundirem-se com os ambientes autorais, [...] as tensões entre autor e participantes podem aumentar" (MURRAY, 2003, p. 248). A pesquisadora, contudo, não proclama a morte do autor e reconhece o papel determinante da autoria na organização entre esses espaços mais ou menos interativos. Menciona, inclusive, a necessidade de "convenções claras" para separar áreas em que os interatores "fossem livres para inventar suas próprias ações" das que "eles não poderiam sequer esperar assumir o controle" (2003, p. 248). Concordamos com Murray e sentimos certo acolhimento teórico na ideia de controle, uma vez que, fiel à base teórica da semiótica francesa, concebemos o texto como produto das escolhas de um enunciador e do fazer interpretativo de um enunciatário.

Tornou-se comum dizer que a noção de texto é afetada diretamente pela ação das novas tecnologias. De acordo com o filósofo da cibercultura Pierre Lévy, o hipertexto "representa sem dúvida um dos futuros da escrita e da leitura" (LÉVY, 1993, p. 19). Em face das reflexões de Lévy, algumas perguntas devem ser postas: em que medida a noção de hipertexto influencia a criação e a circulação das narrativas contemporâneas? A apreensão dos textos narrativos exigirá sempre um tipo de interferência nos enunciados? Vivemos sob o imperativo da relação entre mídias? Nas leituras empreendidas sobre transmidialidade, notamos uma relação estreita entre essa conceituação e a discussão acerca da convergência de meios. 0 entrelaçamento, a retomada, a hibridização, a mistura entre as mídias nos convence a estabelecer relações entre o que se compreende por trans- e intermidialidade. 0 termo intermidialidade costuma ser usado, de modo bastante abrangente, para se referir a fenômenos marcados, nas pa- 
lavras de Claus Clüver, pelo "cruzamento de fronteiras entre mídias" (CLÜVER, 2011, p. 8). De início, podemos nos indagar se nesse "cruzamento" as marcas dessas fronteiras permanecem visíveis ou se diluem e que efeitos de sentido poderiam ser depreendidos pelo apagamento e/ou conservação dessas marcas fronteiriças. É possível, facilmente, notar a diferença da relação verbal/não verbal estabelecida em uma HQ e em um logotipo. Vale ressaltar que análises semióticas já se ocuparam em discutir se há ou não sincretismo verbovisual em logotipos, dada a dificuldade de precisar se neles interagem duas linguagens ou se apenas são expandidas as qualidades expressivas da linguagem verbal ${ }^{1}$.

Irina Rajewsky (2012) propõe uma interessante tipologia sobre a intermidialidade, dividindo-a em três subcategorias, que podemos resumir rapidamente por meio de três palavras: combinação, referências e transposição. A "combinação" engloba os casos em que o texto mobiliza duas ou mais mídias, como a ópera, o teatro ou cinema, ao que, em semiótica, denominamos semióticas sincréticas. A “combinação" é encarada em semiótica como a relação entre múltiplas linguagens postas em sincretismo, em uma mesma enunciação, originando textos multimodais. As "referências intermidiáticas" dizem respeito à evocação ou citação de técnicas de uma mídia em outra, como, por exemplo, o uso de técnicas cinematográficas em um romance, que arriscamos a considerar como uma intermidialidade da expressão. Já a transposição se refere às adaptações entre mídias, em que há uma relação "genética" entre texto-fonte e texto-alvo, as denominadas traduções intersemióticas.

Ao relacionar a classificação de Rajewsky com a discus-

1 Conferir especialmente as análises de Teixeira e Carmo Jr. (In: OLIVEIRA; TEIXEIRA, 2009). 
são sobre as fronteiras, percebemos que, na intermidialidade por "combinação", há uma maior diluição dos contornos de cada mídia. No teatro musical, por exemplo, a relação entre a música e o diálogo é íntima, pressuposta e estabilizada pelo gênero. Já nas referências intermidiáticas, em que são evocadas qualidades técnicas, expressivas e materiais de uma mídia em outra, vê-se que as fronteiras são, pelo contrário, postas em relevo e a apreensão das citações interpostas interfere na significação do texto. No caso das transposições, tradução de um mesmo conteúdo por meio de um outro veículo de expressão, a relação entre as mídias é atravessada pelo transpositor, que pode escolher conservar ou se afastar dos propósitos enunciativos do texto-fonte. As transposições podem ser, então, marcadas por maior ou menor referência, isto é, pode haver acentuação ou atenuação da intermidialidade da expressão com o texto-fonte. Contudo nada garante, por exemplo, que um romance advindo de um game conservará as estratégias interativas constitutivas do jogo.

Fontanille (2007) propõe alguns caminhos de abordagem da intermidialidade, destacando que o gênero pode ser usado para estabelecer uma espécie de hierarquia entre as mídias em relação. Uma peça de teatro (mídia acolhedora) pode abarcar, por exemplo, uma projeção cinematográfica (mídia acolhida). De modo aproximado, Yvana Fechine (2013), ao analisar o uso da transmidialidade na teledramaturgia brasileira, fala em mídia regente, onde se desenvolveria o texto de referência, a partir do qual se articulariam outras mídias. Continuando o raciocínio sobre a categoria do gênero como porta de acesso à intermidialidade, Fontanille propõe, ainda, que se observe o estilo, a fim de estabelecer um percurso a partir dos diferentes graus de convenção ou de inovação entre as associações, que iriam das mais estabilizadas (congeladas) - 
a música e o diálogo teatral na ópera - às mais incongruentes (inesperadas), como a colagem de excrementos humanos em uma instalação artística (FONTANILLE, 2007, p. 107). Salientemos que a associação mais incongruente mencionada por Fontanille diz respeito, mais propriamente, a uma colagem matérica, posta pelo autor no continuum da intermidialidade.

No artigo em que analisa a relação entre linguagem e interdisciplinaridade, Fiorin (2008) inventaria o sentido dos prefixos in-, multi-, pluri-, inter-, trans- na formação de palavras relacionadas aos cruzamentos entre disciplinas. Interessa-nos particularmente, aqui, as observações do semioticista acerca dos prefixos inter- e trans-:

[...] inter < en (denota "dentro de", "entre" e ocorre, por exemplo, em interior, íntimo, interno, entrar, intestino); [...] trans < ter (quer dizer, "atravessar, chegar ao fim" e ocorre em termo, término, determinar, traduzir, transportar, trás-os-montes e assim por diante) (FIORIN, 2008 p. 37).

O mapeamento etimológico feito por Fiorin nos auxilia na empreitada de diferenciar o que se compreender por inter- e transmidialidade. A intermidialidade evocaria tanto uma espacialidade interna (dentro de), como se vê na "combinação" de Rajewsky, quanto um espaço em relação (entre), como se vê nas ideias de "referências" e "transposição". Já o prefixo trans- traz consigo o sentido de atravessamento, de transporte, que podemos compreender como um deslocamento entre diferentes espaços. Nas narrativas transmidiáticas, esses espaços podem ser a televisão, a internet, o espaço da casa onde se faz uma filmagem que possivelmente possa integrar um dos capítulos de novela, o espaço do próprio corpo do sujeito, suporte de camisas e fantasias de personagens em cujos universos os fãs buscam habitar. Jenkins, ao analisar 
a projeto transmídia Matrix, evidencia a ideia de deslocamento e transporte:

Os cineastas plantam pistas que só farão sentido quando jogarmos o game. Abordam uma história paralela, revelada por uma série de curtas de animação que precisam ser baixadas da web e vistas num DVD separado. Os fãs saíram correndo dos cinemas, pasmos e confusos, e se plugaram nas listas de discussão da internet, onde cada detalhe era dissecado e cada interpretação possível, debatida (JENKINS, 2008, p. 137, grifos nossos).

O deslocamento espacial do enunciatário transmidiático, que move o corpo e a atenção para completar as lacunas narrativas, confere ao enunciatário o papel de coletor de pistas e aponta para um tipo de engajamento ativo. 0 enunciatário não tem acesso a um todo acabado de sentido. Lacunas o fazem perscrutar pistas em universos labirínticos. Interessante notar que, quase sempre, a interpretação não fica restrita à esfera subjetiva, mas pressupõe a troca e a colaboração. Essa interpretação colaborativa relaciona-se diretamente ao que Pierre Lévy compreende como um dos "principais motores da cibercultura" (LÉVY, 1999, p. 28), a inteligência coletiva.

Retomemos, uma vez mais, o artigo de Rajewsky, em que a pesquisadora alemã aponta para um sentido mais geral da intermidialidade, que diz respeito a todos os variados tipos de relações entre as mídias. Isso permitiria diferenciar a intermidialidade dos fenômenos intra e transmidiáticos. A intramidialidade é exemplificada por Clüver como "uma mistura de gêneros" (CLUVER, 2011, p. 12) dentro uma mesma mídia. Já a transmidialidade implicaria, segundo Rajewski (2012, p. 18), no "aparecimento de um certo motivo, estética ou discurso em uma variedade de mídias diferentes". A autora exemplifica 
que a estética futurista foi realizada de forma transmidiática, pois pode ser percebida em diferentes mídias (texto verbal, pintura, escultura), conservando, contudo, os "meios formais de cada mídia". Acentuamos, aqui, o caráter transversal da transmidialidade, de sorte que um conteúdo possa ser materializado, retomado, replicado, e mesmo expandido em diferentes plataformas. A nosso ver, a transmidialidade, por meio das articulações que promove, não deixa de implicar em uma intermidialidade, isto é, uma relação entre mídias, ao menos no nível da circulação dos conteúdos e do estabelecimento de práticas sociais relacionadas. Podemos mencionar, por exemplo, o uso do celular como plataforma de produção de vídeo, aliado ao domínio de programas de edição e montagem de vídeos, que fazem parte de ações transmidiáticas usadas na TV transmídia e na "ciberpublicidade" (ATEM; TORRES, 2013) Nesse exemplo, a estratégia transmidiática põe em relação o acesso a sites, o manejo de equipamentos de filmagem, a competência para editar e postar vídeos. Tudo isso exige relações entre mídias. 0 artigo de Fiorin, citado anteriormente, traz um alerta que nos obriga a pensar com mais cuidado sobre essa relação inter- e transmidialidade, já que para ele: "Não se criam diferentes palavras para expressar o mesmo sentido" (FIORIN, 2008, p. 36). Assim, a despeito da falta de rigor nas delimitações desses conceitos ou de um consenso terminológico acerca do fenômeno das relações entre mídias, o fato é que o emprego de duas palavras indicia que estamos diante de duas realidades. Aproximadas pela "midialidade" que põem em jogo, quais seriam as especificidades das relações denotadas pelos termos intermidialidade e transmidialidade?

A transmidialidade abarca um conjunto de estratégias e práticas. De acordo com Fechine, o fenômeno da transmidiação é: 
[...] um modelo de produção orientado pela distribuição em distintas mídias e plataformas tecnológicas de conteúdos associados entre si e cuja articulação está ancorada em estratégias e práticas interacionais propiciadas pela cultura participativa estimuladas pelo ambiente de convergência (FECHINE et al., 2013, p. 26).

A associação entre os conteúdos distribuídos em diferentes meios parece ser um ponto importante na diferenciação entre fenômenos inter- e transmidiáticos. Na intermidialidade, considerados seus diferentes subtipos, as relações entre as mídias convergem para uma mídia central em que se transmite o conteúdo: o livro que abriga técnicas do cinema, o game que é fruto da adaptação de um filme, as HQs que se constroem na relação entre imagem e palavra. Já a transmidialidade, embora possa fazer uso de relações intermidiáticas, diferencia-se justamente pelo deslocamento entre diferentes mídias e espaços que impõe ao enunciatário. Pressupõe-se, na transmidiação, a imagem de um enunciatário em ação.

\section{Do texto à estratégia}

As noções de estratégias e práticas vêm sendo tratadas na semiótica, especialmente, por meio das formulações de Fontanille, ao propor que não só os enunciados podem ser analisados, mas "a própria práxis semiótica 'a enunciação em ato'” é passível de análise e descrição, visto que desenvolve "uma atividade de esquematização" (FONTANILLE, 2008, p. 16). Ao apresentar um percurso hierárquico dos níveis de pertinência, composto por seis instâncias formais, que vão dos signos às formas de vida, o semioticista amplia a dis- 
cussão sobre a expressão, relacionando, segundo Portela "a forma da expressão à substância da experiência e a forma do conteúdo à substância da existência" (PORTELA, 2008, p. 98). Com isso, vemos que, para Fontanille, a expressão prevê um corpo sensível em interação com objetos e com outros sujeitos, ocupando "o espaço tridimensional de uma cena" (FONTANILLE, 2008, p. 28).

A hierarquia dos níveis de pertinência é composta por seis instâncias formais: (1) Figuras-signos, (2) Textos-enunciados, (3) Objetos, (4) Cenas práticas, (5) Estratégias, (6) Formas de vida. 0 exemplo dado por Fontanille, para ilustrar a "integração semiótica entre diferentes planos de imanência", mostra que, em uma carta, o nome e o endereço do destinatário participam de duas práticas: constituem uma instrução para os intermediários postais e permitem triar entre todos os receptores possíveis o destinatário legítimo. Vemos, então, dois tipos de prática: uma do gênero carta e a outra da "comunicação e circulação dos objetos em sociedade" (FONTANILLE, 2008, p. 25). A projeção das marcas de uma prática como simulacro de um fazer pode ser exemplificada na simulação do ato de passar as páginas de um livro que o e-book apresenta. Simula-se o movimento e até a sonoridade do passar das páginas. Com isso, o objeto busca recobrar as propriedades sensíveis e materiais do livro. Não se trata apenas de "transmitir" um livro por outro meio; trata-se de recuperar uma situação semiótica. Essa expansão do nível de pertinência da análise semiótica acolhe carinhosamente objetos complexos como os "textos" produzidos na cibercultura, com suas múltiplas plataformas e modos diversos de interação.

A cultura participativa pode ser vista como uma espécie de "destinador transcendente" (GREIMAS; COURTÉS, 2008, p. 255) que regula a práxis e manipula em favor do dever e 
do desejo de participação, já que "é por seu intermédio, pela força transitiva de sua atuação, que as narrativas não param" (TATIT, 2010, p. 20). Embora o conceito de destinador se localize no nível narrativo da análise semiótica, alargamos a compreensão conceitual por considerarmos a narrativa como encenação da interação mais ampla entre enunciador e enunciatário. Nesse contexto, as narrativas transmidiáticas são concebidas como projetos que preveem um engajamento da atenção, mais cognitivo e passional, que se une a um engajamento da ação, mais somático. Landowski (2014), sobre a interação por manipulação, adverte:

“Procurar assim fazer o outro colaborar com o próprio projeto é, portanto, convidá-lo a aceitar uma maneira determinada de hierarquizar os valores. Em pequena escala, é, em outras palavras, contribuir para construir uma axiologia comum, uma comunidade de julgamento" (LANDOWSKI, 2014, p. 93).

Operando com vários modos de interação e com a construção coletiva dessa "axiologia comum", o fato é que as narrativas transmidiáticas só progridem como projeto enunciativo se os enunciatários previstos aderirem e realizarem com rigor os protocolos e as ações a eles destinadas. Tais protocolos supõem a leitura de textos sincréticos, a manipulação de objetos diversos (computadores, livros, jornais, celulares, câmeras fotográficas, mouses, teclados, etc.) e, portanto, a realização de diferentes práticas semióticas.

Em estudo sobre a transmidialidade na teledramaturgia brasileira, Yvana Fechine mapeou as ações transmídias de todas as telenovelas da rede Globo exibidas em 2012, chegando à proposição de duas categorias gerais de estratégias: propagação e expansão. A estratégia de propagação seria definida 
pela ressonância e retroalimentação dos conteúdos (FECHINE, 2013, p. 33). Já as estratégias de expansão abarcariam os "procedimentos que completam e/ou desdobram o universo narrativo para além da televisão" (2013, p. 34). As estratégias de propagação perduram há algum tempo e demandam, digamos, uma participação mais branda: acompanhar notícias em sites, revistas ou na própria TV sobre os conteúdos a serem exibidos (antecipação) ou já exibidos (recuperação). Ler no portal da emissora informações adicionais sobre o contexto histórico em que se desenvolve a trama (contextuais) ou acessar informações de bastidores que envolvem a produção da novela, aspectos da vida íntima dos atores (promocionais). A nosso ver, as estratégias de propagação constituem estratégias de manipulação com vistas a garantir a continuidade do contrato fiduciário, por meio da manutenção da atenção à narrativa. As estratégias de expansão dizem respeito mais propriamente ao projeto transmídia, e são compostas por conteúdos de extensão textual, em que "programas narrativos se desdobram e se desenvolvem em outros meios a partir do programa principal exibido na TV" (2013, p. 45). Fechine caracteriza a "extensão diegética", em que informações complementares relacionadas ao "mundo ficcional" contribuem para que o enunciatário amplie a experiência narrativa, pelo acesso a conteúdos de "extensão lúdica" que abarcam concursos, games, passatempos, entre outros, contribuindo para uma alternância entre ficção e realidade (FECHINE, 2013, p. 45) Os conteúdos, denominados de extensão impõem maior engajamento de ação, como observaremos em algumas estratégias transmidiáticas usadas na telenovela.

A novela Geração Brasil, exibida pela Rede Globo em 2014, é um caso em que a emissora apostou bastante em estratégias transmidiáticas. A trama é desenvolvida em torno do 
protagonista Jonas Marra, um brasileiro que constrói carreira de sucesso nos Estados Unidos. Ao enfrentar uma crise em sua empresa, Jonas Marra decide voltar ao Brasil e lançar um reality show para jovens talentos da tecnologia, a fim de escolher um sucessor para liderar a empresa.

Figura 1 - Jonas Marra apresenta o reality show

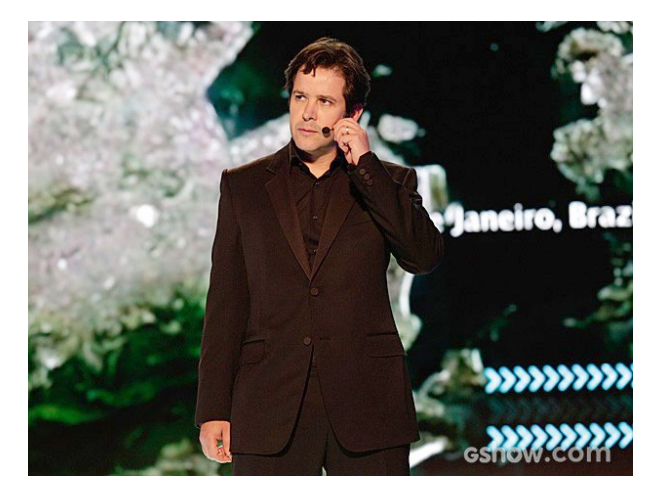

Fonte: GShow (http://gshow.globo.com).

A opção pela temática da tecnologia funcionou como motivo para o desenvolvimento de estratégias. Ao retomar outros gêneros televisivos como reality shows e programas de auditório, a novela empreendeu relações intramidiáticas, que foram expandidas pelo projeto transmídia. Na última fase do reality show de Jonas Marra, a tarefa dada aos personagens de Manuela e Davi, finalistas do fictício reality, era que o aplicativo Filma-e!, desenvolvido pela dupla, tivesse sucesso. 0 aplicativo foi efetivamente disponibilizado para sistemas iOS e Android. Havia inclusive um tutorial para download e uso do aplicativo disponível no site da novela. 
Figura 2 - Manuela e Davi no reality show da novela Geração Brasil.

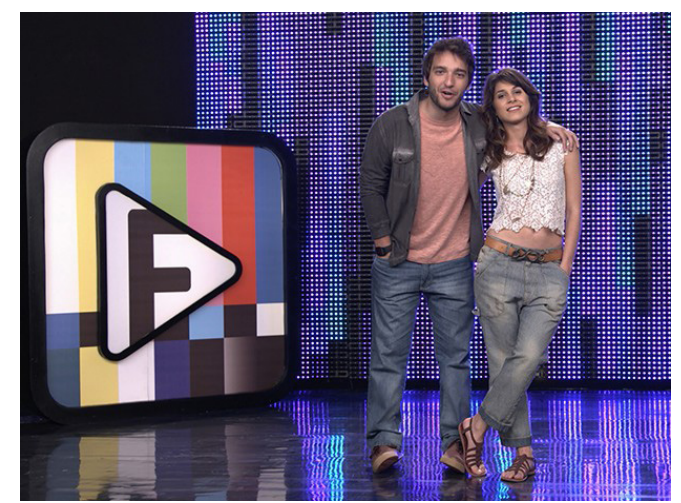

Fonte: GShow (http://gshow.globo.com).

A cada episódio da novela, os personagens lançavam desafios para que o público produzisse vídeos de resposta, usando o aplicativo. Os melhores vídeos poderiam ser exibidos durante os capítulos da novela. A manutenção de desafios para que o público produzisse vídeos no aplicativo configurou um modo de interação por "manipulação", no qual "o manipulador em potencial, atribui a seu parceiro, [...] um estatuto semiótico idêntico ao que reconhece para si mesmo: o de um sujeito" (LANDOWSKI, 2014, p. 27). No período de oito dias em que a copa do mundo interrompeu a emissão da novela, pequenas chamadas apresentadas pelos personagens antecediam o episódio para exibição dos melhores vídeos enviados pelos internautas. Essas e outras estratégias transmídias, como "webséries", sites de diferentes personagens e vendas de produtos fictícios da empresa Marra Brasil circundaram os episódios televisivos. No texto-enunciado da novela, havia 
uma intensa convocação temático-figurativa da tecnologia, personagens usando smartphones, computadores, sites e drones; uso de elementos de expressão, como grafismos, cores e desenhos que invocam a tecnologia, interferência na imagem da TV das mensagens de celular - que apareciam na tela - recebidas pelos personagens, vinhetas de passagem do tempo com movimentos que imitavam cliques, presença de links, estrutura de websites e toda sorte de imagens que faziam referência ao universo dos games e da robótica.

Voltando às formulações de Fontanille sobre as práticas semióticas, vemos que o semioticista preconiza uma dimensão retórica do percurso proposto, por meio do que denomina integrações ascendentes e descendentes, que podemos entender como passagens de um nível de pertinência a outro. Assim, o percurso prevê operações de integração ascendentes (dos signos às formas de vida) e descendentes (das formas de vida aos signos) (FONTANILLE, 2008, p. 30). 0 percurso canônico ascendente é marcado pelo desdobramento e o percurso descendente pela condensação. Ao tomar o enunciado da novela Geração Brasil, vê-se que práticas relacionadas ao uso das novas tecnologias aparecem condensadas e representadas no nível do texto. Essa condensação é desdobrada no nível superior, o dos objetos, quando a manipulação posta no enunciado convoca o enunciatário a manipular objetos diversos (câmeras, smartphones, aplicativos), na vida real. A partir disso, o enunciatário converte-se em um sujeito operador de cenas predicativas assim resumidas: assistir ao episódio, acessar o site, baixar o aplicativo, executar filmagens, enviar os vídeos. Todas essas cenas retornam, de modo condensado, ao texto, através do vídeo de resposta, perfazendo, então, um percurso descendente. Esses movimentos de desdobramento e condensação são orquestrados e previstos em um nível ainda mais superior, o da estratégia, que se textua- 
liza, no caso em análise, através de múltiplas plataformas. 0 uso da transmidialidade na telenovela é uma estratégia que busca adesão do público e fortalecimento dos produtos produzidos pela emissora. Para que as etapas desse percurso de ascendência e posterior descendência se realizem, é preciso, como alertou Landowski, do sólido compartilhamento de valores comuns: o desejo de participar, de deixar a posição de enunciatário para se integrar e se misturar corporalmente ao enunciado, de alcançar projeção e popularidade. Vê-se, ainda, como consequência dessa estratégia, um enfraquecimento da fronteira entre realidade e ficção ou, em outras palavras, um novo modo de conceber a narrativa, de sorte que as práticas sejam representadas e, em função do engajamento ativo do enunciatário, efetivamente, atualizadas no enunciado.

\section{Considerações Finais}

Fontanille (2007) aponta para a necessidade de a semiótica dar conta de uma caracterização do ato de linguagem por meio do qual um meio é convocado e posto no interior de outro (Fontanille, 2007, p. 108). Esse ato de linguagem é constitutivamente complexo, já que há múltiplas possibilidades de construção de objetos intermidiáticos, em função de diferentes suportes, práticas e estratégias significativas. 0 desenvolvimento de uma "semiótica das práticas" vem ao encontro dessas preocupações, visto que o modo como as narrativas transmidiáticas são produzidas e apreendidas depende do conjunto de ações, percepções e escolhas do sujeito contemporâneo, condenado a compreender textos formados em uma complexa rede de significações. Acreditamos que tal modo de construção de objetos significativos impõe grandes desafios às teorias do texto e do discurso. Diante disso, propomo-nos 
a incorporar o recorte epistemológico que elege o estudo das práticas significantes, visto que:

A construção de uma semiótica das práticas conduz ao mesmo tempo a descobrir novos domínios de investigação e a ver de uma outra maneira os domínios que acreditávamos conhecer ou dominar (FONTANILLE, 2008, p. 36).

Notamos que a produção de obras ficcionais midiáticas tem sido regida pelo imperativo da intermidialidade. 0 emprego em larga escala da intermidialidade erige uma práxis enunciativa que euforiza a citação de diferentes mídias, a mescla de procedimentos próprios a múltiplos suportes e materialidades, a incorporação dos meios expressivos de diferentes linguagens.

Este trabalho buscou aprofundar a discussão teórica, sob o ponto de vista da semiótica, acerca de conceitos como intermidialidade e transmidiação. Por meio da observação do caso da novela Geração Brasil, percebe-se que os projetos transmidiáticos complexificam a imagem do enunciador pressuposto, por meio da ampliação de papéis a serem desempenhados em diferentes espaços midiáticos. Essa complexificação fica nítida em projetos desenvolvidos por grandes conglomerados, cujas estratégias, geralmente, reúnem o controle de emissoras de TV, jornais impressos e on-line, revistas, portais, sites, canais e páginas em redes sociais. Por outro lado, as narrativas transmidiáticas delimitam e determinam com precisão ações e tarefas a serem cumpridas pelos destinatários. Acredita-se ainda que a transmidialidade, como parte integrante da cultura participativa, prevê uma adesão profundamente colaborativa e ativa e, por isso, reflete um conjunto de valores reveladores das formas de vida contemporâneas. 


\section{REFERÊNCIAS}

ATEM, G. N.; TÔRRES, S. A Ciberpublicidade: ensaio de sociossemiótica. In: TEIXEIRA, Lucia; CARMO JR., José Roberto (Orgs.). Linguagens na cibercultura. São Paulo: Estação das Letras e Cores, 2013. p. 1-25.

BERGEN, Franz Von. Venezuela faz ofensiva nas redes sociais com funcionários que gerenciam até $\mathbf{5 0}$ perfis falsos. 0 Globo. Disponível em: <http://oglobo.globo.com/mundo/ venezuela-faz-ofensiva-nas-redes-sociais-com-funcionariosque-gerenciam-ate-50-perfis-falsos-16661502?utm_ source $=$ Fa ce b o o k $\&$ u t m_m edium $=$ S o cial $\&$ u t m campaign=compartilhar\&fb_ref=Default $>$. Acessado em: 20 ago. 2015.

CLÜVER, Claus. Intermidialidade. Pós. Belo Horizonte, v.1. n.2, p. 8-23, nov, 2011.

FONTANILLE, Jacques. Significação e visualidade: exercícios práticos. Porto Alegre: Sulina, 2005.

FONTANILLE, Jacques. Intermidialité: l'affiche dans l'annoncepresse. In. BADIR, Sémir; ROELENS, Nathalie (Orgs.). Visible: Intermidialité visuelle. Limoge: Pulim, 2007.

FONTANILLE, Jacques. Práticas Semióticas. In: DINIZ, Maria Lúcia V. P.; PORTELA, Jean Cristtus (Orgs.). Semiótica e Mídia. Bauru: UNESP/FAAC, 2008.

FECHINE, Yvana et al. Como pensar os conteúdos transmídias na teledramaturgia brasileira? Uma proposta de abordagem a partir das telenovelas da Globo. In. LOPES, Maria Immacolata 
Vassalo de (Org.). Estratégias de transmidiação na ficção televisiva brasileira. Porto Alegre: Sulina, 2013. p. 19-60.

FIORIN, José Luiz. Linguagem e interdisciplinaridade. Alea: Estudos Latinos, Rio de Janeiro, v. 10, n.1, p. 29-53, 2008.

GREIMAS, A, J.; COURTÉS, J. Dicionário de semiótica. São Paulo: Contexto, 2008.

JENKINS, Henry. Cultura da convergência. São Paulo: Aleph, 2008.

LANDOWSKI, Eric. Interações arriscadas. São Paulo: Estação das Letras e Cores; Centro de Pesquisa Sociossemióticas, 2014.

LÉVY, Pierre. Cibercultura. São Paulo: Ed. 34, 1999.

LÉVY, Pierre. As tecnologias da inteligência. Rio de Janeiro: Ed. 34, 1993.

MURRAY, Janet. Hamlet no Holodeck: o Futuro da Narrativa no Ciberespaço. São Paulo: Itaú Cultural: UNESP, 2003.

OLIVEIRA, Ana Claudia; TEIXEIRA, Lucia (Orgs.). Linguagens na comunicação: desenvolvimentos de semiótica sincrética. São Paulo: Estação das Letras e Cores, 2009.

PORTELA, Jean Cristtus. Semiótica midiática e níveis de pertinência. In: DINIZ, Maria Lúcia V. P.; PORTELA, Jean Cristtus (Orgs.). Semiótica e Mídia. Bauru: UNESP/FAAC, 2008. 
RAJEWSKY, I. O. Intermidialidade, intertextualidade e "remediação": uma perspectiva literária sobre a intermidialidade. In. DINIZ, T. F. N. (Org.). Intermidialidades e estudos interartes. Belo Horizonte: UFMG, 2012. p. 15-43.

TATIT, Luiz. Semiótica à luz de Guimarães Rosa. São Paulo: Ateliê Editorial, 2010.

Artigo recebido em maio de 2016 e aprovado em julho de 2016.

\section{Como citar este trabalho:}

SOUSA, Silvia Maria de. A transmidialidade como estratégia discursiva. CASA: Cadernos de Semiótica Aplicada, São Paulo, v. 14, n. 01, p. 241-263, julho, 2016. Disponível em: <http://seer.fclar.unesp.br/casa>. Acesso em "dia/mês/ano". http://dx.doi.org/10.21709/casa.v14i1.8015. 